\title{
The Incidence of Cytomegalovirus Infection in Lung Transplant Recipients under Universal Prophylaxis with Intravenous Ganciclovir
}

\author{
Regina Schröeder ${ }^{1}$, Tatiana Michelon', João Wurdigi,2, Iara Fagundes ${ }^{1}$, Sadi Schio ${ }^{3}$, Leticia Sanchez ${ }^{3}$, \\ José J. Camargo ${ }^{3}$, Teresa C. Sukkienik ${ }^{4}$, Alessandro C. Pasqualotto ${ }^{4,5}$ and Jorge Neumann ${ }^{1}$ \\ ${ }^{1}$ Laboratory of Transplant Immunology, Santa Casa Complexo Hospitalar, Porto Alegre, Brazil, ${ }^{2}$ Universidade do Vale do Rio dos Sinos \\ (UNISINOS), São Leopoldo, Brazil, ${ }^{3}$ Pulmonary Transplant Unit, Santa Casa Complexo Hospitalar, Porto Alegre, Brazil, ${ }^{4}$ Infection Control \\ Department, Santa Casa Complexo Hospitalar, Porto Alegre, Brazil, ${ }^{5}$ School of Medicine, University of Manchester, UK
}

\begin{abstract}
The best strategy for control of cytomegalovirus (CMV) infection in lung transplant patients is still not determined. The aim of this study was to document the incidence of CMV infection in a cohort of lung transplant recipients under universal prophylaxis with intravenous ganciclovir. All patients received immunosuppressive regimens consisting of cyclosporine, azathioprine, and prednisone. Regardless of CMV serostatus, intravenous ganciclovir was prescribed for every patient in the first 3 months post-transplantation. CMV infection was defined as the detection of CMV pp65 in leukocytes. Eighty-two lung transplant patients were included over a 5-year period. The incidence of CMV infection in the first year post-transplantation was 68.3\%, occurring after a median length of 114 days (range, 26-343 days). This study revealed a high incidence of CMV infection in the first year following lung transplantation despite prolonged universal ganciclovir prophylaxis.
\end{abstract}

Key-Words: Cytomegalovirus, antigenemia, lung transplantation, ganciclovir, prophylaxis.

Cytomegalovirus (CMV) is a major concern in immunosuppressed patients, particularly in the context of solid organ transplantation (SOT). The incidence of CMV infection and disease is higher in lung transplant recipients than in other SOT patients, with reported rates of $54 \%$ to $92 \%$ in the absence of CMV prophylaxis [1,2]. Based on these findings, most preventive approaches to date have involved universal prophylaxis with ganciclovir in which all patients receive prophylaxis for a pre-determined duration. However, this strategy is very controversial. Data against universal prophylaxis include drug-related toxicities (mainly hematological), costs, and necessity of vascular accesses. In addition, it has been reported that $0 \%-13 \%$ of transplant patients receiving ganciclovir develop secondary resistance to this drug [3]; rates as high as $27 \%$ has been reported in $\mathrm{D}^{+} /$ $\mathrm{R}^{-}$lung transplant recipients [4]. Moreover, the diagnosis of resistance is not easy, requiring modern technologies, and few therapeutic options are available for the treatment of ganciclovir-resistant CMV. The aim of this study was to determine the incidence of CMV infection 1 year after lung transplantation in a population of patients submitted to universal prophylaxis with intravenous ganciclovir over a 5year period.

\section{Materials and Methods}

This retrospective cohort study was conducted in Santa Casa Complexo Hospitalar, a 1,200-bed Brazilian tertiary hospital and reference center for SOT in South America. Patients submitted to lung transplantation between March

Received on 11 October 2006; revised 3 March 2007.

Address for correspondence: Dr. Regina Schröeder. Laboratory of Transplant Immunology, Santa Casa Complexo Hospitalar. Av. Independência, 75. Zip code: 94035-075. Porto Alegre, RS, Brazil. Phone (55 51) 3214-8600. E-mail: regina@santacasa.tch.br.

The Brazilian Journal of Infectious Diseases

2007;11(2):212-214. (C) 2007 by The Brazilian Journal of Infectious Diseases and Contexto Publishing. All rights reserved.
1999 and February 2004 were eligible for study. All patients received triple immunosuppressive regimens consisting of cyclosporine, azathioprine, and prednisone. A protocol of universal prophylaxis with intravenous ganciclovir was adopted, regardless of CMV serostatus, as follows: $10 \mathrm{mg} / \mathrm{kg} /$ daily for the 3 weeks post-transplantation, followed by $5 \mathrm{mg} /$ $\mathrm{kg} /$ daily for the weeks 4 to 12 . CMV infection was defined as the detection of CMV pp65 in leukocytes using monoclonal antibodies (Clonab-Biotest, Germany) [5], and the results of the antigenemia test were reported as the number of positive cells per $10^{5}$ circulating granulocytes. Patients were monitored weekly for the presence of pp65 antigenemia between weeks 3 and 12 following transplantation (the period of higher risk for CMV infection), and then every 15 days in the months 4 to 12 post-transplant. Additional testing was performed according to clinical suspicion. Due to the absence of data related to CMV infection, patients who died in the first month following lung transplantation were excluded from the analysis. Descriptive statistics were used to summarize the data.

\section{Results}

During the period of study, 106 lung transplants were performed in our institution. Twenty-four patients (22.6\%) were excluded due to the occurrence of death in the first month following transplantation, resulting in 82 patients for analysis. Most of these patients were male (65.9\%), and mean age was 51.2 years-old (range, 7-72 years-old). Donor source was cadaveric-related in $92.7 \%$.

The incidence of CMV infection in the first year posttransplantation was $68.3 \%(\mathrm{n}=56)$. For these patients, median number of positive cells was $11.4 / 10^{5}$ granulocytes (range, $1 /$ $10^{5}-1,096 / 10^{5}$ cells). Most of the patients (53.6\%) had counts higher than 10 cells $/ 10^{5}$ granulocytes. The first positive test following transplantation occurred after a median length of 114 days (range, 26-343 days). No difference was observed regarding gender, age, and donor status (cadaveric- or living- 
related) among patients who developed a positive CMV antigenemia test and those who did not.

The overall mortality in the first year after transplantation was $37.8 \%(n=40)$, and no difference in the mortality rate was observed when patients were stratified according to the occurrence of CMV infection $(p=0.204)$ or to the number of positive infected granulocytes $(\mathrm{p}=0.128$ for counts higher or lower than $10 / 10^{5}$ cells).

\section{Discussion}

Our results showed a high incidence of CMV infection after lung transplantation (68.3\%), despite a policy of prolonged universal prophylaxis with intravenous ganciclovir. Similarly, previous studies have revealed that antiviral prophylaxis does not avoid but postpone the occurrence of CMV infection [6-12]. Nevertheless, this delay may be deleterious. Following cessation of prophylaxis, the virus may then be detected in a time when the typical patient is relatively well and undergoing outpatient visits, potentially leading to a late diagnosis with associated higher viral loads [13]. In addition, treatment of late CMV infection with intravenous ganciclovir may produce a tardy response of viral load due to resistant virus within the population. Such issues do not arise with preemptive therapy since the duration of treatment is much shorter than that required to select for resistance [14]. The pp65 antigenemia test is a very fast, sensitive and specific method for the diagnosis of CMV infection in SOT patients [15-17]. The probability of CMV disease in a patient with a negative antigenemia test is close to zero [15]. In our institution, the experience with pp65 antigenemia test in renal transplant recipients as a preemptive tool revealed an incidence of CMV infection and disease of $60 \%$ and $38 \%$, respectively, in the first 3 months post-transplant [18]. At this moment, preemptive therapy is strongly being considered for lung transplant recipients in our medical center as well.

Although there is a paucity of strong data on the efficacy and safety of preemptive therapy compared with those of universal prophylaxis in lung transplant recipients [19], some centers have followed a preemptive approach to the management of these patients, which has been shown to be safe and effective [20-22]. Theoretically, a preemptive approach might be expected to be associated with lower rates of resistance, because antiviral therapy is specifically targeted to patients considered to be at risk (rather than to all patients) [3]. Given the availability of the pp65 antigenemia test and the limitations of the anti-CMV drugs currently existing, preemptive therapy seems to offer the best way to minimize unnecessary drug exposure while ensuring that CMV disease is controlled and allowing cost-effective use of limited resources [13]. Furthermore, antiviral prophylaxis was not shown to reduce mortality or the incidence of bronchiolitis obliterans syndrome following lung transplantation [12,23], which are major concerns.

In conclusion, this study revealed a considerably high incidence (68\%) of CMV infection in the first year following lung transplantation despite prolonged universal prophylaxis with intravenous ganciclovir. We believe that universal prophylaxis should be reserved to the group of patients under higher risk of CMV infection, i.e. those with $\mathrm{D}^{+} / \mathrm{R}^{-}$serostatus. For the others, the use of preemptive therapy based on a sensitive test such as pp65 antigenemia may be a reasonable option. Randomized clinical trials are expected to answer this question.

\section{Acknowledgements}

Dr. Pasqualotto is sponsored by CAPES (Brazilian government). The authors declare no conflict of interest.

\section{References}

1. Duncan A.J., Dummer J.S., Paradis I.L., et al. Cytomegalovirus infection and survival in lung transplant recipients. J Heart Lung Transplant 1991;10:638-44.

2. Ettinger N.A., Bailey T.C., Trulock E.P., et al. Cytomegalovirus infection and pneumonitis: impact after isolated lung transplantation. Am Rev Respir Dis 1993;147:1017-23.

3. Limaye A.P. Ganciclovir-resistant cytomegalovirus in organ transplant recipients. Clin Infect Dis 2002;35:866-72.

4. Limaye A.P., Raghu G., Koelle D.M., et al. High incidence of ganciclovir-resistant cytomegalovirus infection among lung transplant recipients receiving preemptive therapy. J Infect Dis 2002; $185: 20-7$

5. Ljungman P., Griffiths P., Paya C. Definitions of cytomegalovirus infection and disease in transplant recipients. Clin Infect Dis 2002;34:1094-7.

6. Gane E., Saliba F., Valdecasas G.J., et al. Randomised trial of efficacy and safety of oral ganciclovir in the prevention of cytomegalovirus disease in liver transplant recipients. The Oral Ganciclovir International Transplantation Study Group. Lancet 1997;350:1729-33.

7. Lowance D., Neumayer H.H., Legendre C.M., et al. Valacyclovir for the prevention of cytomegalovirus disease after renal transplantation. International Valacyclovir Cytomegalovirus Prophylaxis Transplantation Study Group. N Engl J Med 1999;340:1462-70.

8. Limaye A.P., Corey L., Koelle D.M., et al. Emergence of ganciclovir-resistant cytomegalovirus disease among recipients of solid-organ transplants. Lancet 2000;356:645-9.

9. Fishman J.A., Doran M.T., Volpicelli S.A., et al. Dosing of intravenous ganciclovir for the prophylaxis and treatment of cytomegalovirus infection in solid organ transplant recipients. Transplantation 2000;69:389-94.

10. Razonable R.R., Rivero A., Rodriguez A., et al. Allograft rejection predicts the occurrence of late-onset cytomegalovirus (CMV) disease among CMV-mismatched solid organ transplant patients receiving prophylaxis with oral ganciclovir. J Infect Dis 2001; $184: 1461-4$.

11. Gerbase M.W., Dubois D., Rothmeier C., et al. Cost and outcomes of prolonged cytomegalovirus prophylaxis to cover the enhanced immunosuppression phase following lung transplantation. Chest 1999;116:1265-72.

12. Hertz M.I., Jordan C., Savik S.K., et al. Randomized trial of daily versus three-times-weekly prophylactic ganciclovir after lung and heart-lung transplantation. J Heart Lung Transplant 1998; $17: 913-20$.

13. Emery V.C. Prophylaxis for CMV should not now replace preemptive therapy in solid organ transplantation. Rev Med Virol 2001; $11: 83-6$.

14. Emery V.C, Griffiths P.D. Prediction of cytomegalovirus load and resistance patterns after antiviral chemotherapy. Proc Natl Acad Sci USA 2000;97:8039-44. 
15. Schroeder R., Michelon T., Fagundes I., et al. Antigenemia for cytomegalovirus in post renal transplantation: choosing a cut off for the diagnosis criteria in cytomegalovirus disease. Transplant Proc 2005;37:2781-3.

16. Schroeder R., Mesko J., Santos A., et al. Cytomegalovirus antigenemia and renal function post-kidney-transplantation. Transplant Proc 1999;31:3027-8.

17. Schroeder R., Michelon T., Fagundes I., et al. Comparison between RFLP-PCR and antigenemia for pp65 antigen for diagnosis of cytomegalovirus after kidney transplantation. Transplant Proc 2004;36:891-3.

18. Schroeder R., Michelon T., Fagundes I., et al. Cytomegalovirus disease latent and active infection rates during the first trimester after kidney transplantation. Transplant Proc 2004;36:896-8.

19. Zamora M.R., Davis R.D., Leonard C. Management of cytomegalovirus infection in lung transplant recipients: evidencebased recommendations. Transplantation 2005;80:157-63.
20. Egan J.J., Lomax J., Barber L., et al. Preemptive treatment for the prevention of cytomegalovirus disease: In lung and heart transplant recipients. Transplantation $1998 ; 65: 747-52$.

21. Gerna G., Baldanti F., Lilleri D., et al. Human cytomegalovirus pp67 mRNAemia versus pp65 antigenemia for guiding preemptive therapy in heart and lung transplant recipients: A prospective, randomized, controlled, open-label trial. Transplantation 2003;75:1012-9.

22. Kelly J., Hurley D., Raghu G. Comparison of the efficacy and cost effectiveness of pre-emptive therapy as directed by CMV antigenemia and prophylaxis with ganciclovir in lung transplant recipients. J Heart Lung Transplant 2000;19:355-9.

23. Perreas K.G., McNeil K., Charman S., et al. Extended ganciclovir prophylaxis in lung transplantation. J Heart Lung Transplant 2005;24:585-7. 